\title{
EUFORIA E DISFORIA DO /R/ RETROFLEXO DA APRESENTADORA ANA MARIA BRAGA
}

\section{EUPHORIA AND DYSPHORIA OF ANA MARIA BRAGA'S RETROFLEX /R/}

\author{
Conrado Moreira Mendes e Ana Cristina Fricke Matte \\ UFMG - Universidade Federal de Minas Gerais
}

\begin{abstract}
Resumo: Neste artigo analisamos de que maneira a adoção do /R/ retroflexo pela apresentadora do programa Mais Você, Ana Maria Braga, pode ter um valor eufórico, ao passo que o /R/ glotal, velar ou tepe teria um valor disfórico. Numa segunda situação, o /R/ glotal, velar ou tepe poderá ter um valor eufórico, enquanto o retroflexo teria um valor disfórico. Tais categorias semânticas de base circunscrevem-se ao nível fundamental do percurso gerativo de sentido, descrito pela teoria semiótica francesa.
\end{abstract}

Palavras-chave: semiótica francesa; plano da expressão; nível fundamental; euforia/disforia; /R/ retroflexo; Mais Você.

\begin{abstract}
In this article we analyze the ways in which the adoption of the retroflex /R/ by Ana Maria Braga, the host of the Brazilian female TV program Mais Você, can have a euphoric value, whereas the glottal, velar or flap /R/ would have a dysphoric value. In a second situation, the glottal, velar or flap /R/ will have a euphoric value, while the retroflex would have a dysphoric value. Such basic semantic categories are related to the fundamental level of the meaning generative process, described by the French semiotic theory.
\end{abstract}

Keywords: French semiotics; expression plan; fundamental level; euphoria/dysphoria; retroflex /R/; Mais Você.

\section{Introdução}

Nosso objeto de análise é o programa feminino comandado pela apresentadora Ana Maria Braga, Mais Você, veiculado pela TV Globo às 8 h e 5 min, desde julho de 1999. Especificamente, pretende-se perceber os efeitos de sentido que podem criar alguns alofones do arquifonema ${ }^{1} / \mathrm{R} /$ usados pela apresentadora Ana Maria Braga. Buscamos apreender de que

\footnotetext{
${ }^{1} \mathrm{O}$ arquifonema representa todas as possibilidades de realização de um mesmo fonema e cada possibilidade é denominada alofone.
} 
maneira ela faz uso do /R/ retroflexo $[\ell]^{2}$ (caipira), para criar um efeito de aproximação, positivo, portanto. Em outra situação, a apresentadora lança mão da pronúncia do /R/ velar $[\mathrm{X}]$, glotal [h] ou tepe [r], que causa um efeito de neutralidade quase jornalística, ou seja, também um efeito de valor eufórico. Nosso referencial teórico-metodológico é a semiótica greimasiana, que nos dá suporte para estudar tanto fenômenos inscritos no âmbito do plano de conteúdo, como aqueles que se inscrevem no âmbito do plano da expressão.

\section{“Mais Você" e Programas femininos}

De acordo com Temer (2005), os programas femininos são versões das revistas femininas impressas, um gênero bem antigo, cujo início remonta ao ano de 1693, na Inglaterra ${ }^{3}$. Foi, no entanto, a Lady's Magazine que, já no século XX, em 1928, consolida o termo magazine, "oferecendo entretenimento, esclarecimento e serviço" (TEMER, 2005, p. 02). Periódicos voltados ao público feminino têm em comum o fato de apresentarem alguns componentes básicos tais como culinária, moda, decoração, comportamento, temas em relação à família, etc. No Brasil, o primeiro periódico feminino foi lançado em 1827, o Espelho Diamantino. Mas é somente em 1914 que a Revista Feminina dá novo impulso ao segmento.

A televisão, no Brasil, desde sua gênese, já traz programas voltados ao público feminino, adaptações do formato consagrado por esse tipo de publicação. Os primeiros programas, Revista Feminina e No Mundo Feminino, coincidem com o início da televisão no Brasil, a década de 1950. Na década de 1980, a Rede Globo inaugura um novo formato para o público feminino: o $T V$ Mulher, comandado pela jornalista Marilia Gabriela, pela então sexóloga Marta Suplicy e pelo estilista Clodovil Hernandes, entre outros. Programas como o TV Mulher, de acordo com o site TV Brasil ano 50, foram um reflexo das transformações sociais pós-década de 1970 e não se limitaram apenas a questões domésticas, mas incluíram discussões como os direitos da mulher, a sexualidade, o posicionamento feminino na sociedade, a mulher como profissional, etc.

Na década de 1990, Ana Maria Braga chama atenção à frente do programa da Rede Record Note e Anote, e recebe inclusive a premiação no Guinness Book, como a apresentadora que mais horas esteve no ar. Em 1999, assina contrato com a Rede Globo e dá início ao Mais Você, até hoje no ar. A apresentadora levou para a Globo os moldes de seu programa popular(esco), que se poderia chamar de uma versão atualizada do programa de Ofélia Anunciato, apresentadora por mais de 30 anos de A Cozinha Maravilhosa de Ofélia, pela TV Bandeirantes. Temer (2005) corrobora essa idéia, afirmando: "No conjunto do programa, a culinária ainda predomina" (p. 10). A ambientação do programa em muito se assemelha a uma casa, com uma cadela poodle chamada Belinha e um papagaio (este, um fantoche interpretado pelo ator Tom Veiga). Desse lugar, que cria um efeito de domesticidade, a apresentadora faz entrevistas e chama reportagens, algumas realizadas por ela própria.

O estilo do Mais Você talvez se aproxime mais ao do programa de Ofélia Anunciato, que do TV Mulher, que apresentava alguns traços de ideologia feminista. Apesar disso, de acordo com Scofield (2007, p. 122-3), o Mais Você não enfatiza um modelo único de mulher, baseado num padrão patriarcal do século XVIII:

\footnotetext{
${ }^{2}$ Símbolos da Associação Internacional de Fonética.

${ }^{3}$ De acordo com Temer (2005), Lady's Mercury foi a primeira revista voltada ao público feminino na Inglaterra (1693).
} 
Bem ou mal, de maneira profunda ou superficial, o programa abre um espaço historicamente negado às mulheres (...) Ao contrário de reiterar um saber masculino, racional e científico, o Mais Você busca se fundamentar em narrativas conversacionais, centrando-se muitas vezes no emocional e no particular, fazendo com que as vozes das convidadas sejam ouvidas pelas telespectadoras

Existe, por assim dizer, uma brecha pela qual as telespectadoras do Mais Você têm alguma voz e há também uma pluralidade, em certa medida, nas formas de representação dessas mulheres.

Após essa incursão aos programas femininos e, mais especificamente, ao Mais Você, trataremos de um tema mais denso, sob o ponto de vista teórico: o plano da expressão e o nível fundamental. O primeiro se refere a uma parte da função semiótica, da qual se origina o signo lingüístico; o segundo trata de um nível do percurso gerativo do sentido, descrito pela teoria semiótica francesa. Um e outro são fundamentais para entender a proposta deste artigo, que é perceber os efeitos de sentido do /R/ retroflexo utilizado pela apresentadora desse programa feminino de caráter popular. Entendemos que esse fato lingüístico está imbricado com vários outros, de natureza sociológica, antropológica, ideológica e midiática, em suma, culturais. Vem daí nossa preocupação de abarcar também aquilo que circunda e tangencia o fato lingüístico em si.

\section{Plano da expressão}

Louis Hjelmslev parte da idéia saussuriana de que todo signo lingüístico é a relação entre um significante e um significado. Na língua falada, o primeiro é a imagem acústica - de ordem fonológica e, o segundo, um conceito, de ordem semântica. A relação, portanto, não é de palavras e coisas, mas entre grandezas lingüísticas. Hjelmslev, grosso modo, denomina significado de plano do conteúdo (conceito) e significante de plano da expressão (imagem acústica, no caso da língua falada). Não se trata de uma simples substituição de nomenclatura em relação ao que Saussure chamou de significante e significado, mas de uma mudança de concepção.

Para Hjelmslev, tanto o plano do conteúdo quanto o plano da expressão subdividem-se em forma e substância. A substância refere-se ao continuum, tanto no plano do conteúdo, que é o continuum do pensamento, quanto no da expressão, continuum de sons da língua. A forma, por sua vez, tem a ver com o modo como cada cultura recorta seu pensamento em palavras (conteúdo), e em fonemas (expressão). Segundo Hjelmslev, o que une a expressão ao conteúdo é a função semiótica. Essa função é solidária e necessariamente um plano pressupõe o outro: "Uma expressão só é expressão porque é expressão de um conteúdo, e um conteúdo só é conteúdo porque é conteúdo de uma expressão" (HJELMSLEV, 1975, p. 54). De modo esquemático, temos: 


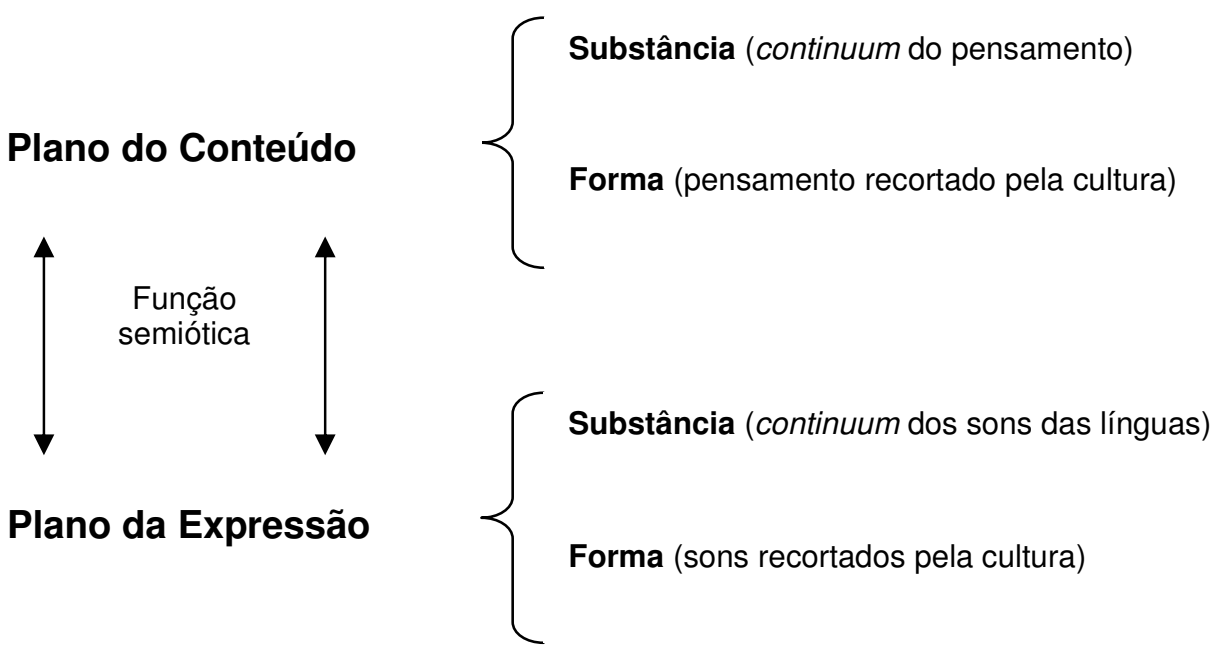

Esquema I: Planos da expressão e conteúdo

Em outras palavras, para Floch (1985, p. 01):

O plano da expressão é aquele em que as qualidades sensíveis, que uma linguagem usa para se manifestar, são selecionadas e articuladas entre si por desvios diferenciais. O plano do conteúdo é aquele em que a significação nasce dos desvios diferenciais com os quais cada cultura, para pensar o mundo, ordena e encadeia idéias e narrativas.

A substância, tanto do plano de expressão, quanto do plano de conteúdo, constitui-se um elemento dessemantizado, que só passa a ter sentido quando recortada por cada cultura, tornando-se "forma". Portanto todos os sons passíveis de serem produzidos pelo trato vocal humano só passam a ter sentido após a identificação com elementos que nada mais são que recortes culturais do continuum sonoro colocados em uma sequiência pertinente à língua em questão. Dessa maneira, de acordo com Hjelmslev (1975), o sentido assume diferentes cadeias lingüísticas em cada língua. A sentença $E u$ não sei, em português, veicula o mesmo sentido que a sentença Jeg véd det ikke, em dinamarquês, ou I do not know, em inglês. Para esse lingüista, cada uma dessas línguas estabelece suas fronteiras de maneira distinta no continuum do pensamento.

Nesse sentido, podemos dizer que a forma do conteúdo é arbitrária e apenas explicável pela função semiótica que une o conteúdo à expressão. Assim, podemos falar de um sentido da expressão. No caso de alguém que fala uma língua estrangeira com sotaque, Hjelmslev afirma que se "trata de formar um sentido da expressão conforme as condições funcionais sugeridas pela língua materna do elocutor" (HJELMSLEV, 1975, p. 61).

Para esse lingüista, embora seja algo contrário ao habitual, já que se convencionou falar apenas do sentido do conteúdo, deve-se considerar também que a expressão carrega consigo um sentido. Pensar o sotaque, nessa perspectiva, é assumir que ele produz sentido. Para Medeiros, "se o sotaque produz sentidos, ele é, em si, informação revela elementos componentes do ambiente local" (MEDEIROS 1999, p. 188). Assim, este artigo busca perceber os sentidos construídos pelo plano da expressão na língua oral, ou seja, por meio da adoção de um ou outro alofone do arquifonema /R/, como faz a apresentadora Ana Maria Braga.

Passemos agora ao nível fundamental para perceber de que maneira tais sentidos são construídos no âmbito do plano da expressão. Fez-se importante, para tanto, 
entender de que trata o plano de expressão, uma vez que, no nível fundamental, ele também remeterá ao plano do conteúdo. Ou seja, o uso de um /R/ retroflexo implicaria um conteúdo (categoria semântica de base), com valor eufórico ou disfórico, de acordo com cada situação.

\section{Nível fundamental}

"O objeto da semiótica é o sentido", diz Bertrand (2003, p. 11), apreensível pelo resultado da função semiótica da linguagem, ou seja, a reunião dos planos da expressão e do conteúdo. O que diferencia essa disciplina de outras, como a história ou antropologia, que também podem ter o sentido como objeto é "o parecer do sentido" (BERTRAND, ibidem). Tal parecer se apreende por meio da linguagem verbal, não-verbal (visual, plástica, gestual, musical etc.) ou sincrética, como, por exemplo, o cinema, que agrupa algumas dessas linguagens. A semiótica francesa, desenvolvida por Algirdas Julien Greimas (1917-1992), lingüista lituano radicado na França, tem filiação saussuriana e hjelmsleviana, por isso, está ancorada numa teoria da linguagem, de postulados estruturais, e na concepção de que a língua é uma instituição social.

Para a semiótica, um texto pode ser fatiado em camadas, pelas quais se dá o percurso gerativo de sentido, que se estrutura do mais simples e abstrato ao mais complexo e concreto. Temos, assim, nessa ordem, o nível fundamental (profundo), o narrativo (intermediário) e o discursivo (superficial).

No nível fundamental, a significação se apresenta por uma oposição semântica, ou seja, estruturas fundamentais que se opõem. Para Barros (2003), os termos dessa oposição são determinados pelas nossas relações sensoriais com esses conteúdos, que podem ter um valor positivo (eufórico) ou negativo (disfórico). Tais termos são negados e afirmados por meio de operações de sintaxe elementar, e podem ser representados por meio de um modelo lógico de relações, chamado quadrado semiótico.

Assim, podemos ter categorias semânticas fundamentais em oposição, tais como vida $v s$ morte, liberdade $v s$ submissão, etc. A disforia ou euforia de uma categoria semântica não se dá de antemão, mas se constrói no e pelo texto. Assim, morte não é necessariamente uma categoria disfórica, nem vida, uma categoria eufórica a priori. Um suicida, para quem viver é insuportável, tem a morte como categoria semântica eufórica, por exemplo. Isso porque, de acordo com Tatit (2006, p. 199),

(...) o ser vivo não se relaciona com (...) categorias semânticas sem nelas imprimir sua marca sensível. (...) de acordo com o contexto de exame, todo microuniverso semântico contém um índice axiológico (...), portador de valores considerados atraentes ou repulsivos.

No quadrado semiótico, um estado A não se converte em um estado $\mathrm{B}$, sem antes passar pela negação do próprio estado A. Euforia e disforia são, de acordo com esse autor, articulações da categoria foria, que significa "força que leva adiante". A categoria eufórica encontra-se em estado de relaxamento, ao passo que a disfórica em estado de tensão. Do mesmo modo, a categoria não-disfórica encontra-se num estado de distensão, enquanto a não-eufórica, em estado de retensão. Dessa forma, atribui-se um caráter tensivo, dinâmico, ao quadrado semiótico, que vai além das relações de asserção e de negação. 


\section{Situações de realização do /R/ em "Mais Você"}

Percebe-se, durante o programa Mais Você, dois momentos distintos em relação ao uso dos alofones do /R/ pela apresentadora Ana Maria Braga, que pode ser tanto retroflexo, como glotal, velar e, em alguns casos mais raros, tepe. De acordo com Silva (2001), com relação à posição de travamento silábico, a consoante retroflexa alveolar vozeada ( $\mathrm{R}$ retroflexo) é a pronúncia típica da variedade caipira. Já as fricativas velar e glotal (vozeadas ou não) são aquelas relativas à pronúncia do /R/ dos dialetos carioca e belohorizontino, respectivamente. $\mathrm{O}$ tepe alveolar vozeado, por sua vez, remete a algumas variedades, tais como a paulistana.

Percebe-se que os alofones do /R/ glotal, velar e tepe pertencem a variedades ligadas ao espaço urbano, enquanto o retroflexo pertence ao espaço rural. Sabe-se que a pronúncia da mídia brasileira privilegia um modo de falar que mescla algumas variantes da região sudeste (excetuando o falar caipira), em detrimento de outros falares, como o nortista, nordestino ou sulista. Medeiros corrobora essa idéia, ao dizer: "Há uma tendência generalizada entre os repórteres de emissoras distantes do eixo Rio-São Paulo de modificarem a forma de falar cotidiana, no momento em que pegam o microfone e se posicionam diante de uma câmera de TV" (MEDEIROS, 2006, p. 13). Assim, as variantes do Sudeste teriam um caráter "neutro", enquanto as outras, um caráter marcado. Evidentemente, ninguém acredita que este ou aquele locutor seja neutro. É melhor admitir que a adoção de um modo especial de falar esteja ligada mais a questões ideológicas que lingüísticas ${ }^{4}$.

Antes de passarmos para a esquematização das situações de produção dos alofones do /R/ no programa Mais Você, faremos uma pequena incursão pelo termo caipira, sem a qual não será possível um amplo entendimento sobre o tema.

\section{Algumas considerações sobre o caipira}

Antonio Candido (2001), em sua obra clássica da sociologia brasileira sobre o caipira paulista, afirma que o termo rural "exprime, sobretudo localização" (CANDIDO: 2001, p. 26), enquanto o termo rústico exprime um tipo cultural e social "o que é, no Brasil, o universo das culturas tradicionais do homem do campo; as que resultaram do ajustamento do colonizador português no Novo Mundo" (CANDIDO, Ibidem). Para o autor, no caso brasileiro, o termo rústico se traduz por caboclo. No entanto, para evitar confusões com "mestiço próximo ou remoto de branco e índio, que em São Paulo forma a maioria da população tradicional", o autor prefere o termo caipira. Caipira ("cortador de mato", na língua tupi), mais que indicar uma localização que se refere ao campo, alude principalmente a aspectos culturais da vida desses indivíduos.

Historicamente, a cultura e o modo de vida caipira resultaram da expansão geográfica dos paulistas nos séculos XVI, XVII e XVIII, a partir da ação das bandeiras e entradas. Denominou-se Paulistânia, portanto, o território ocupado por esses indivíduos, procedentes de uma variedade subcultural do tronco português chamada caipira. Essa forma de povoamento caracterizou-se pela dispersão, que favoreceu uma cultura de subsistência. No entanto, essa cultura era sustentada por uma relação estreita com os bairros rurais, a partir dos quais se realizavam as ajudas mútuas, como o escambo ou o mutirão. A cultura caipira, portanto, está ligada "a formas de sociabilidade e de subsistência que se apóiam em soluções

\footnotetext{
${ }^{4}$ Veja MENDES, C. M. O falar do Jornal Nacional: produção e recepção de um sotaque de natureza ideológica. Monografia de conclusão de curso em Comunicação Social. Universidade Federal de Minas Gerais, 2006.
} 
mínimas, apenas para manter a vida dos indivíduos e a coesão dos bairros" (CANDIDO, 2001, p. 103).

Em suma, as principais características da cultura caipira, para Antonio Candido, são: (1) o isolamento; (2) a posse de terras; (3) trabalho doméstico; (4) auxílio vicinal; (5) disponibilidade de terras; (6) margem de lazer. A vida do caipira está, então, intimamente relacionada ao espaço rural, onde se realizam relações de subsistência e de sociabilidade, a partir de "soluções mínimas", especificadas pelo autor. Um fator importante da sociabilidade vicinal é a vida lúdico-religiosa, com atividades que transcendem o âmbito familiar e que se realizam nos bairros e vilas rurais. Não podemos perder de vista a importância da religião católica, das superstições e do folclore para a constituição da cultura caipira.

O caipira, uma vez estabelecidas as formas de equilíbrio social e ecológico, apegou-se a tais formas como expressão de sua identidade. Para Candido, o atraso chamou a atenção de estudiosos estrangeiros, como Saint-Hilaire, e acabou por caracterizar erroneamente - o modo de vida caipira. Essa idéia portanto, mesmo que construída a partir de um ponto de vista etnocêntrico, persiste ainda nos séculos XX e XXI, como vemos pela representação caricatural do caipira no personagem Jeca Tatu, criação literária de Monteiro Lobato. Destacam-se ainda o personagem de histórias em quadrinhos Chico Bento, criado por Maurício de Sousa, e a filmografia de Amácio Mazzaropi, que criou o Jeca nos anos 1950.

\section{Situação 1}

Por uma questão analítica, dividimos em duas situações, ou momentos, de realização do /R/ pela apresentadora Ana Maria Braga. E, ancorados na teoria semiótica francesa, propomos uma disposição no quadrado semiótico, onde opomos a caipirice à urbanidade. De acordo com o Dicionário Houaiss da Língua Portuguesa, o primeiro termo designa "qualidade ou condição do que é caipira", e o segundo, "qualidade ou condição do ser urbano". Preferimos opor a "qualidade do que é caipira" à "qualidade do que é urbano", evitando a dicotomia natureza versus cultura, por entendermos cultura como "(...) uma rede de práticas e de representações implantadas (textos, imagens, conversas, códigos de comportamento e as estruturas narrativas que os organizam) que influencia cada aspecto da vida social" (FROW \& MORRIS, 2006, p. 316). Ou seja, a cultura está também presente no ambiente rural, já que este também se caracteriza como um local de sociabilidade, diferenças e enfretamentos 5 .

Nessa situação de realização, o /R/ retroflexo tem valor eufórico, já que a apresentadora se desveste de uma suposta neutralidade, por meio da adoção desse alofone, que faz parte de seu acento de origem (dialeto caipira, pois a apresentadora é nascida no interior paulista) para se apresentar como a pessoa Ana Maria Braga, e não a apresentadora. Isso tende a criar um efeito de aproximação com o público majoritariamente composto por mulheres donas-de-casa ${ }^{6}$. Essa aproximação ocorre por se tratar de quase uma conversa entre

\footnotetext{
${ }^{5}$ Para S. Hall, a cultura não é o lugar da boa ou dá má, da alta ou da baixa cultura, mas o local do enfrentamento e de lutas sociais. Veja-se HALL, S. Da diáspora: identidades e mediações culturais. Belo Horizonte: UFMG, 2003.

${ }^{6}$ De acordo com a Rede Globo de Televisão, o Mais Você tem audiência de cinco milhões de telespectadores em todo o Brasil, o equivalente a 35\% da audiência nacional voltada para esse formato televisivo. Desses cinco milhões de telespectadores, mulheres representam $51 \%$ da audiência; crianças e jovens de ambos os sexos, com idades que variam de 4 a 17 anos, equivalem a $20 \%$ e os homens correspondem a $29 \%$ da audiência. E $80 \%$ das 
comadres ou vizinhas do interior, ou um ato de contar "causos", típico da cultura caipira. Poderíamos ir além e pensar que esse efeito de aproximação remonta às formas de sociabilidade e subsistência caipiras, nas quais o auxílio vicinal é imprescindível.

$\mathrm{O} / \mathrm{R} /$ glotal, velar ou tepe, nessa situação, teria um valor disfórico, pois criaria um efeito de distanciamento, de não efetivação de laços de sociabilidade entre a apresentadora e o público. Vejamos o quadrado semiótico em que o /R/ retroflexo tem valor eufórico:

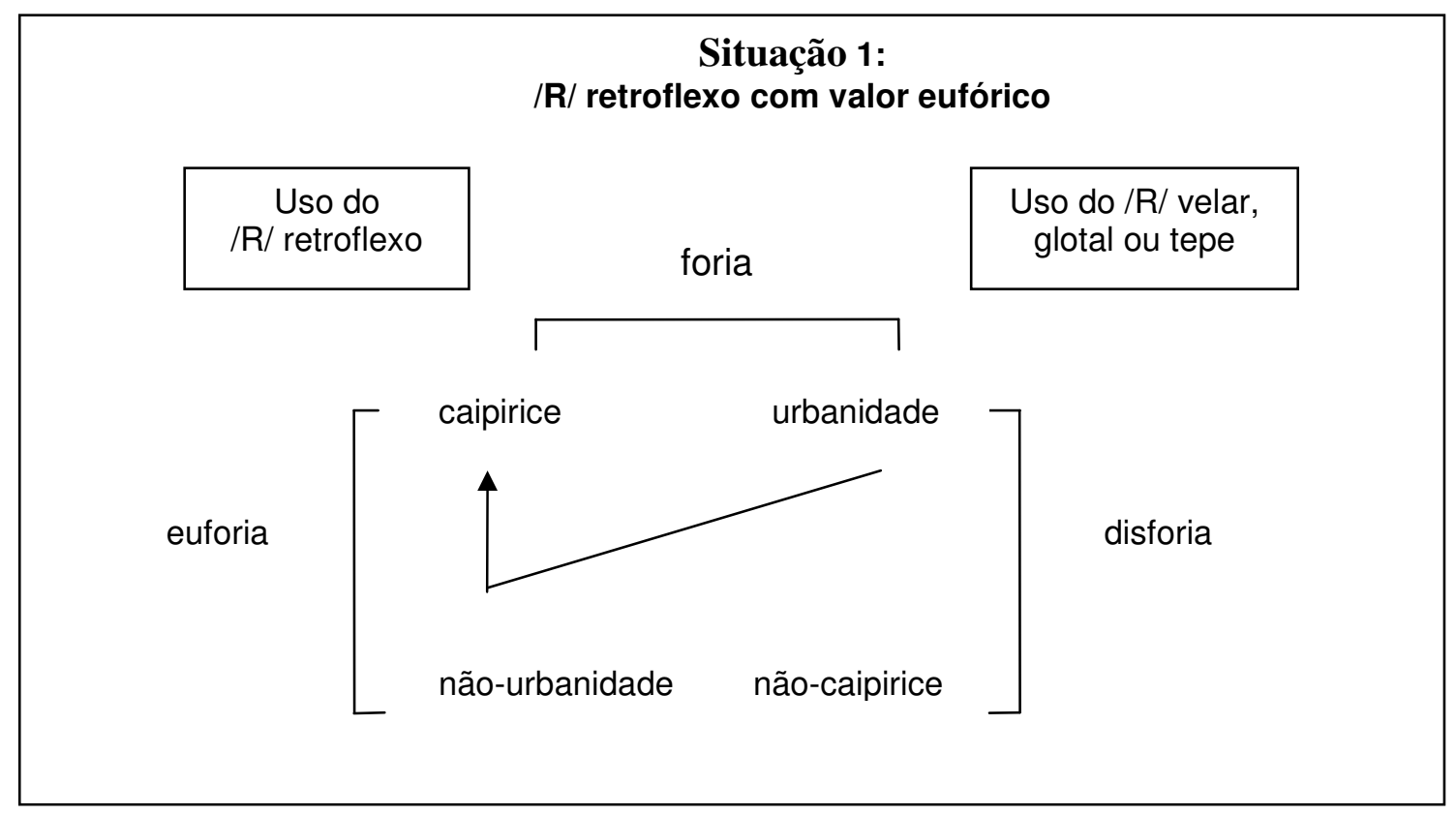

Esquema II: Valor eufórico do /R/ retroflexo.

\section{Situação 2}

No quadrado semiótico a seguir, também opomos caipirice à urbanidade. No entanto, como os valores são axiologizados de maneira contrária, temos um deslocamento também oposto na representação. Nesse segundo momento, o /R/ glotal, velar ou tepe (urbanos) tem valor eufórico, já que cria um efeito de neutralidade, o que supostamente seria o esperado de uma apresentadora (o uso de um acento "neutro", ). Esse valor de neutralidade é eufórico, uma vez que o programa, segundo Temer (2005), apresenta traços marcantes do gênero jornalístico.

Dessa maneira, o uso do /R/ retroflexo, nessa segunda situação, criaria um efeito disfórico, já que remeteria a uma ruralidade indesejável, ou seja, criaria um "efeito jeca" no programa. Pela decoração, pelas vestimentas da apresentadora, por outras semioses, até mesmo por receitas de cozinha apresentadas, o programa Mais Você enquadra-se muito mais num universo urbano que num universo rural. Diferentemente, por exemplo, do

pessoas têm idade superior a 18 anos, sendo que $71 \%$ dos telespectadores estão concentrados nas classes C, D e E. (Dados retirados no site da Rede Globo de Televisão: http://comercial.redeglobo.com.br acesso em 18/07/07)

\footnotetext{
${ }^{7}$ Não se trata de um acento neutro, mas de um acento naturalizado por meio de coerção ideológica. Em outras palavras, trata-se do falar de uma região de maior prestígio econômico e político, que se apresenta como o falar sem sotaque ou não-marcado.
} 
programa Viola, minha viola, comandado por Inezita Barroso, no qual a ruralidade teria um valor eufórico, levando em conta ainda que esses dois programas não pertencem a um mesmo gênero televisivo. Assim se apresenta o segundo quadrado semiótico, no qual o /R/ retroflexo tem valor disfórico:

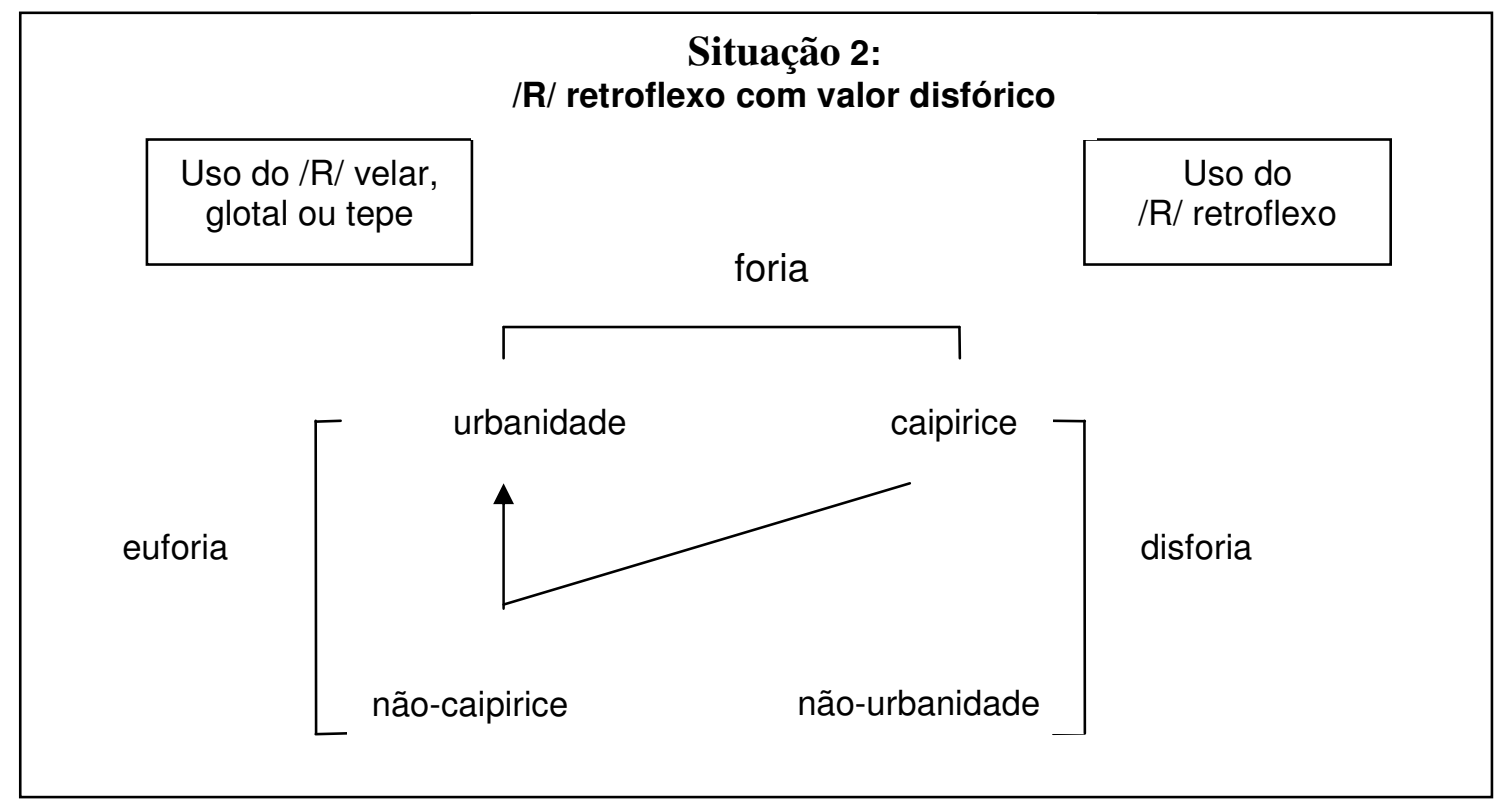

Esquema II: Valor disfórico do /R/ retroflexo.

\section{Conclusão}

Como vimos nos quadrados semióticos apresentados, opuseram-se os termos caipirice e urbanidade, evitando a oposição natureza vs cultura, por razões já explicitadas. Caipira se refere a um modo de vida rural, localizado numa região determinada do Brasil, com um falar característico que é, por sua vez, objeto de inúmeros estudos no âmbito da sociolinguística. Na contemporaneidade, o termo caipirice talvez não se oponha apenas de forma assertiva ou negativa em relação à urbanidade. Muito da chamada cultura caipira se encontra no modo de vida das cidades e vice-versa. Assim, como afirma Tatit (2006), ao quadrado semiótico também é atribuído um caráter tensivo e dinâmico, podendo-se, por meio dele, perceber as nuances e transformações entre esses estados.

Por fim, a partir dessas duas situações, percebemos que o efeito de sentido causado pelo uso do /R/ retroflexo não é de per si eufórico ou disfórico, assim como o uso do /R/ velar, glotal ou tepe. A euforia e disforia são produzidas, como apontou Tatit (2006) num "microuniverso semântico" e, a partir daí, tais valores se atualizam. Tanto o /R/ retroflexo (caipira), como o /R/ velar, glotal ou tepe (urbanos) não remetem a valores positivos ou negativos a priori. As categorias semânticas de base só adquirem um valor eufórico ou disfórico no e pelo discurso. Procurou-se, pois, com este artigo, analisar uma característica pontual do plano da expressão para perceber que o sentido se constrói de inúmeras maneiras. 
CASA, Vol.6 n.2, dezembro de 2008

\section{Referências bibliográficas}

BARROS, D. L. P. de. Estudos do Discurso. In FIORIN, J. L. (Org.). Introdução à lingüística II: princípios de análise. $2^{\mathrm{a}}$ ed. - São Paulo: Contexto, 2003.

BERTRAND, D. Caminhos da semiótica literária. Tradução. do Grupo CASA. Bauru, SP: EDUSC, 2003.

CANDIDO, A. Os parceiros do Rio Bonito: estudo sobre o caipira paulista e as transformações do seu meio de vida. 10ª ed. São Paulo: Duas Cidades; Ed.34, 2001.

FLOCH. J.-M. Alguns conceitos fundamentais em semiótica geral (anexo), Tradução de Mariza B. T. Mendes, apostila (2006), In Petites mytologies de l'oeil et de l'esprit: Pour une sémiotique plastique. Paris-Amsterdam, Hadès-Benjamin, 1985.

FROW, J. \& M., Meaghan. Estudos Culturais. In: DENZIN, N. K. \& LINCOLN, Y.O planejamento da pesquisa qualitativa: teorias e abordagens. Tradução de Sandra Regina Netz. - Porto Alegre: Artmed, 2006.

HJELMSLEV, L. Prolegômenos a uma teoria da linguagem. Tradução de J. Teixeira Coelho Netto São Paulo: Perspectiva, 1975.

HOUAISS, A. Dicionário Houaiss da língua portuguesa. Rio de Janeiro: Objetiva, 2001.

MEDEIROS. A.L. Outros falares, outros olhares: os "sotaques" no telejornalismo e na novela. Dissertação de Mestrado. UnB, 1999. . Sotaques na TV. São Paulo: Anablumme, 2006.

TATIT, L. A abordagem do texto. In FIORIN, J.L. (Org.). Introdução à lingüística. $5^{\mathrm{a}}$ ed. São Paulo: Contexto, 2006.

TEMER, A. C. R. P. Mais Você: uma análise da Revista Feminina na Televisão. In: V Encontro dos Núcleos de Pesquisa da Intercom no XXVIII Congresso Brasileiro de Ciências da Comunicação. NP 07 - Comunicação Audiovisual,

TV Brasil ano 50. Disponível em <http://www.centrocultural.sp.gov.br/tvano50/dec80.htm> Acesso em 18 Jul 2007.

SCOFIELD, T. H. P. Possibilidades do feminino: as telespectadoras de Ponta Porã e as mulheres do Mais Você. Dissertação de Mestrado. Universidade Federal de Minas Gerais: 2007.

SILVA, T. C. Fonética e fonologia do português: roteiro de estudos e guia de exercício. $5^{\mathrm{a}}$ ed. - São Paulo: Contexto, 2001. 